\title{
Carpal tunnel syndrome or C8/T1 radiculoneuropathy due to perinural cyst: A diagnostic conundrum
}

\author{
Vikas Bhatia, Neeraj Balaini', Paramjeet Singh \\ Departments of Radio-Diagnosis and Imaging and ${ }^{1}$ Neurology, PGIMER, Chandigarh, India \\ Correspondence: Dr. Vikas Bhatia, Department of Radio-Diagnosis and Imaging, PGIMER, Chandigarh, India. \\ E-mail:drvikasbhatia@gmail.com
}

\begin{abstract}
Perineural cysts are usually described in Lumbosacral region and are uncommonly seen in cervical spine.These are mostly asymptomatic, with only a few cases of symptomatic cervical perineural cysts. No previous case report of perineural cyst causing C8/T1 radiculoneuropathy mimicking clinically as Carpal tunnel syndrome is reported in the literature. We report a case of elderly female who was operated for presumed Carpal tunnel syndrome. However, her symptoms did not improve. The MRI of the patient revealed presence of perineural cysts at the level of C8/T1 exiting nerve root, compressing it and causing the symptoms. We present the clinical, nerve conduction study and radiological presentation of cervical perineural cyst mimicking Carpal tunnel syndrome in this patient.
\end{abstract}

Key words: Carpal tunnel; MRI; neuropathy; perineural cyst

\section{Introduction}

Perineural or Tarlov cysts are detected incidentally on routine MRI imaging of spine and are commonly found to occur in Lumbosacral region..$^{[1]}$ Occurrence of perineural cyst in cervical region is uncommonly seen with very few case reports. They are largely asymptomatic with only few cases that are reported, showing them to cause Cubital tunnel syndrome ${ }^{[2]}$ or mimicking an intra-spinal tumor. ${ }^{[3]}$ MRI is the investigation of choice to diagnose these lesions and may require additional sequences to delineate the relationship of the cyst with the nerve roots. ${ }^{[2]}$

Carpal tunnel syndrome is an entrapment neuropathy commonly seen in females with peak incidence in 40-60 years with symptoms of paresthesia and numbness in

\begin{tabular}{|l|l|}
\hline \multicolumn{2}{|c|}{ Access this article online } \\
\hline Quick Response Code: & \\
\cline { 1 - 2 } & Website: \\
& www.ijri.org \\
\cline { 2 - 3 } & DOI: \\
\cline { 1 - 2 } & 10.4103/ijri.IJRI_414_20 \\
\hline
\end{tabular}

the median nerve sensory distribution,.eventually causing thenar muscle atrophy. ${ }^{[4]}$

We present a case of elderly female who presented with symptoms mimicking clinically Carpal tunnel syndrome and was operated for the same. However, worsening of the symptoms led to further investigations with MR spine imaging revealing perineural cysts at C8/T1 level.

\section{Case Report}

A 42-year-old female presented with chief complaints of paresthesia and pain in right hand. There was no history of fever or trauma.

This is an open access journal, and articles are distributed under the terms of the Creative Commons Attribution-NonCommercial-ShareAlike 4.0 License, which allows others to remix, tweak, and build upon the work non-commercially, as long as appropriate credit is given and the new creations are licensed under the identical terms.

For reprints contact: WKHLRPMedknow_reprints@wolterskluwer.com

Cite this article as: Bhatia V, Balaini N, Singh P. Carpal tunnel syndrome or $\mathrm{C} 8 / \mathrm{T} 1$ radiculoneuropathy due to perinural cyst: A diagnostic conundrum. Indian J Radiol Imaging 2020;30:510-2.

Received: 07-Jun-2020

Accepted: 01-Sep-2020

Revised: 18-Jul-2020

Published: 13-Jan-2021 
Initially it started with intermittent pinprick sensations and mild pain over right hand below the wrist which gradually progressed to persistent pain and she started having difficulty in using first two digits and the thumb. Initially she was clinically diagnosed as Carpal tunnel syndrome and median nerve decompression at Carpal tunnel was done before presenting to us.However, her symptoms continue to worsen after surgery so she was evaluated further at our institute.

On examination, wasting of right thenar region was present as compared to left side [Figure 1]. There was hyperalgesia over digits of right hand. With a presumed diagnosis of right brachial plexopathy or cervical radiculopathy, nerve conduction studies were performed in this patient. Right median sensory nerve action potential (SNAP) and the compound action muscular potential (CMAP) were not recordable. Right ulnar SNAP was normal, however CMAP was reduced.Right radial, axillary and musculo-cutaneous nerves showed normal SNAP and CMAP values. Right median SNAP was reduced likely because of post op changes resulting in partial nerve injury at local site.

In view of reduced CMAP values in both median and ulnar nerves pathology at C8/T1 radicles or lower brachial plexus was suspected.

Subsequently the patient was referred for MRI examination of right brachial plexus to rule out plexitis/mass lesion.Right Brachial plexus showed normal signal intensity with no abnormal enhancement, thus ruling out clinical possibility of brachial plexitis.

There was presence of well-definedcystic lesion measuring $6.1 \times 3.4 \mathrm{~mm}$ at the level of right C 8/T1 nerve root. Another similar cyst was noted one level higher. These lesions were hypo-intense on T1weighted images and hyper-intense on T2 weighted images [Figure 2]. They were in close relation to the exiting nerve roots [Figure 3]. No e/o any contrast enhancement was seen [Figure 4]. Based on these findings a diagnosis of perineural cyst was made. The patient was managed conservatively. She is currently on follow-up with physiotherapy and shown mild improvement in symptoms. Microsurgical intervention will be planned if there is worsening of symptoms.

\section{Discussion}

The Carpal tunnel syndrome is the commonest entrapment neuropathy with reported incidence up to $1 \%$ of population. ${ }^{[5]}$ It is caused because of compression of the median nerve at the carpal tunnel and is associated with paresthesia and numbness in the median nerve sensory distribution. However, a differential diagnosis of Carpal tunnel syndrome include cervical radiculopathy, pancoast tumor, nerve sheath tumors, thoracic outlet syndrome, lower brachial

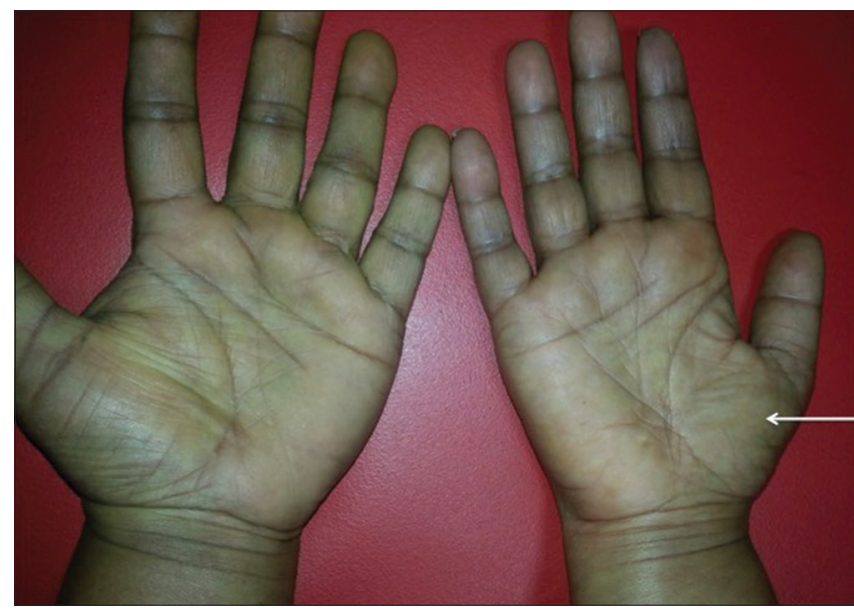

Figure 1: Photograph of both handsshowing atrophy of right thenar region as compared to the left hand (white arrow)
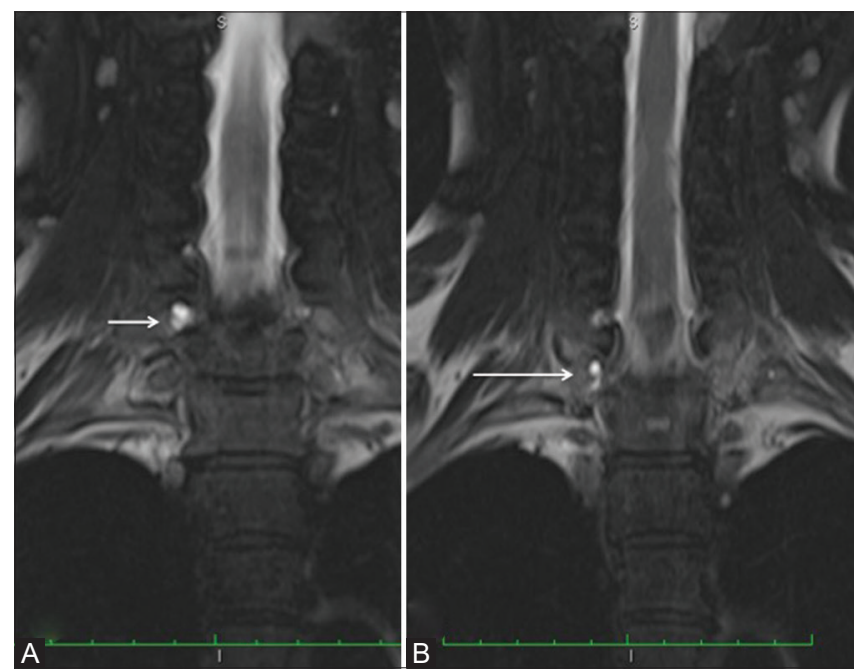

Figure 2 ( $\mathrm{A}$ and $\mathrm{B}$ ): Coronal T2WI images showing Perineural cysts at right $\mathrm{C} 6-\mathrm{C} 7$ (short arrow) and C7-T1 neural foraminas (long arrow)
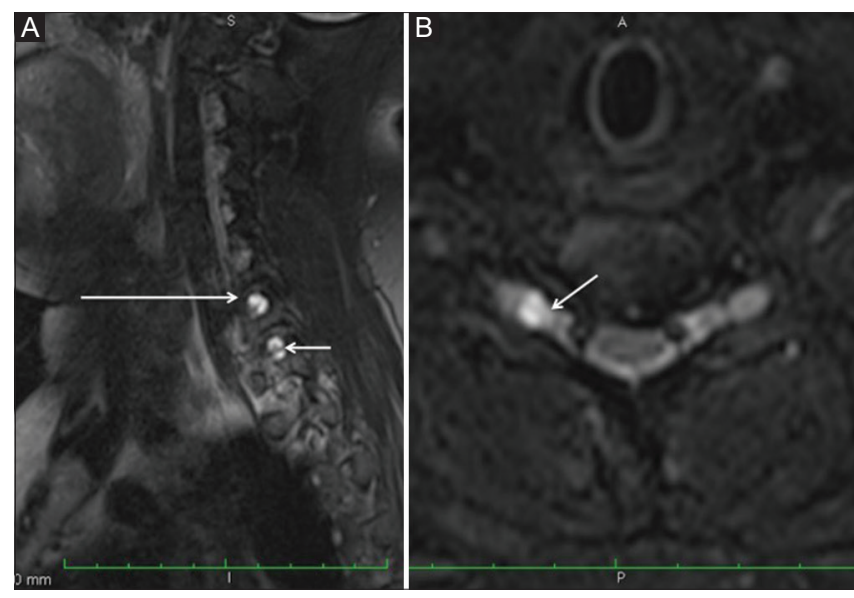

Figure 3 (A and B): Sagittal (A) and Axial (B) T2WI FS images. Sagittal image (A) shows well-defined cysts along the right $\mathrm{C} 7$ (long arrow) and C8 (short arrow) nerve roots with central iso-intense nerve root seen clearly. Axial image (B), at the level of right C7-T1 neural foramina showing perineural cyst along the exiting nerve root (short arrow)

plexopathy, idiopathicbrachioplexitis, syringomyelia, and motor neuron disease. ${ }^{[6]}$ 


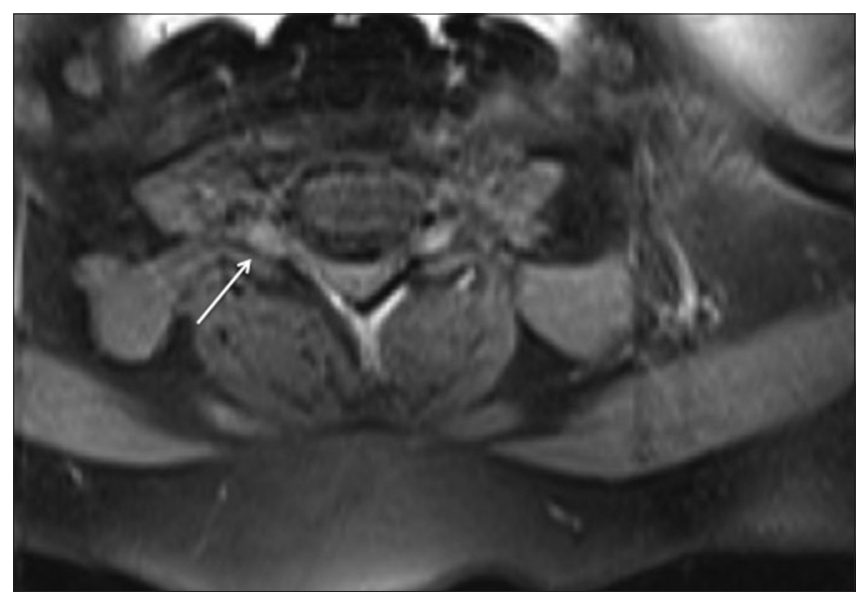

Figure 4: Axial T1W FS post contrast images showing lack of enhancement (arrow) within the lesion

Cervical radiculopathy is commonest mimicker of Carpal tunnel syndrome, however there will be presence of numbness and weakness in proximal dermatomes with associated neck pain, which may be aggravated with motion, coughing, or sneezing. Cervical syringomyelia has characteristic dissociative sensory loss. Thoracic outlet syndrome produces symptoms predominantly in ulnar nerve distribution. In case of idiopathic brachial plexitis there is usually prodromal phase of severe pain in proximal limb, followed by weakness in one or more peripheral nerves with no specific distribution pattern. ${ }^{[6]}$

Perineural cysts are cystic CSF filled dilatation between the perineurium and endoneurium of nerve roots. They are commonly seen at the lumbo-sacral level and are usually asymptomatic. ${ }^{[7]}$ Rarely these may cause symptoms related to nerve root compression causing radiculopathy, pain, paraesthesia and even bowel or bladderdysfunction.Cervical perineural cysts mimicking as tumor and even presenting as cubital tunnel syndrome has been reported before..$^{[2,3]}$

The cause of the enlargement of the cyst is attributed to active secretion of the inner cells of the cyst, the osmotic gradient between the arachnoid membrane and cyst, the pulsation of CSF, and the formation of a valve between the cyst and subarachnoid space with the last one appearing to be the most convincing theory. ${ }^{[8,9]}$

MRI is modality of choice for evaluating signal characteristics of perineural cysts that have CSF like intensity on T1 and T2-weighted images with lack of contrast enhancement andalso to evaluate the relationship ofthe cyst to the thecal sac and exiting nerve root. Associated findings such as fluid volume in the cyst and presence of adjacent mass effect resulting in bone erosion or neural foramina enlargement can also be accurately visualized..$^{[2]}$

On imaging, diseases, which are included in the list of differential diagnosis of perineural cyst are meningeal diverticula and meningeal pouch. Pseudo-meningocele is another potential differential diagnosis, however is usually associated with trauma. ${ }^{[10]}$

The treatment of symptomatic cysts is largely controversial and includes surgical decompression; computed tomography guidedpercutaneous and epidurally injected steroids. ${ }^{[11]}$

In conclusion, the characteristic location along the nerve fibers established the diagnosis of perinueural cyst in this present case.These cysts though largely asymptomatic may result in varied clinical presentation including atypical presentations such as Carpal tunnel syndrome.MRI of cervical spine including brachial plexus should be included in standard workup of entrapment neuropathies.

\section{Declaration of patient consent}

The authors certify that they have obtained all appropriate patient consent forms. In the form the patient(s) has/have given his/her/their consent for his/her/their images and other clinical information to be reported in the journal. The patients understand that their names and initials will not be published and due efforts will be made to conceal their identity, but anonymity cannot be guaranteed.

Financial support and sponsorship

Nil.

\section{Conflicts of interest}

There are no conflicts of interest.

\section{References}

1. Tarlov IM. Perineurial cysts of the spinal nerve roots. Arch Neurol Psychiatry 1938;40:1067-74.

2. Bayrakli F, Kurtuncu M, Karaarslan E, Ozgen S. Perineural cyst presenting like cubital tunnel syndrome. Eur Spine J 2012;21(Suppl 4):S387-9.

3. JoshVP, Zanwar A, Karande A, Agrawal A. Cervical perineural cyst masquerading as a cervical spinal tumor.Asian Spine J 2014;8:202-5.

4. Dawson DM, Hallett M, Wilbourn AJ. Entrapment neuropathies. Philadelphia, New York: Lippincott-Raven; 1999.

5. Aroori S, Spence RA. Carpal tunnel syndrome. Ulster Med J 2008;77:6-17.

6. Amadio P. Differential diagnosis of carpal tunnel syndrome. In: Luchetti R, Amadio P, editors.Carpal Tunnel Syndrome. Springer; 2007. p. 89-94.

7. Paulsen RD, Call GA, Murtagh FR. Prevalence and percutaneousdrainage of cysts of the sacral nerve root sheath (Tarlov cysts).AJNR Am J Neuroradiol 1994;15:293-7.

8. Cloward RB. Congenital spinal extradural cysts: Case report with review of literature. Ann Surg 1968;168:851-64.

9. Chaiyabud P, Suwanpratheep K. Symptomatic Tarlov cyst: Report and review. J Med Assoc Thai 2006;89:1047-50.

10. Rankine JJ. Adult traumatic brachial plexus injury.Clin Radiol2004;59:767-74.

11. Mitra R, Kirpalani D, Wedemeyer M. Conservative management of perineural cysts. Spine (Phila Pa 1976). 2008;33:E565-8. 